\title{
Minimum Ten-Year Outcome of a Triple-Tapered Femoral Stem Implanted With Line-To-Line Cementing Technique
}

Hirotsugu Ohashi ( $\nabla$ hohashi@grace.ocn.ne.jp )

Saiseikai Nakatsu Hospital

Satoshi lida

Matsudo City General Hospital

Izumi Minato

Niigata Rinko Hospital

\section{Research Article}

Keywords: Total hip arthroplasty, Triple-tapered polished femoral stem, Line-to-line cementing technique, Subsidence

Posted Date: March 10th, 2021

DOI: https://doi.org/10.21203/rs.3.rs-258121/v1

License: (c) (i) This work is licensed under a Creative Commons Attribution 4.0 International License. Read Full License 


\title{
Minimum ten-year outcome of a triple-tapered femoral stem implanted with line-to-line cementing technique
}

\author{
Hirotsugu Ohashi, $\mathrm{MD}^{1}$, Satoshi Iida, $\mathrm{MD}^{2}$, Izumi Minato, $\mathrm{MD}^{3}$ \\ ${ }^{1}$ Department of Orthopaedic Surgery, Osaka Saiseikai Nakatsu Hospital \\ 2-10-39 Shibata, Kita-ku, Osaka 530-0012, Japan \\ ORCID: 0000-0003-2938-6149 \\ 2 Department of Orthopaedic Surgery, Matsudo City General Hospital \\ 933-1 Sendabori, Matsudo, Chiba 270-2296, Japan \\ ORCID: 0000-0003-4784-7543 \\ ${ }^{3}$ Department of Orthopaedic Surgery, Niigata Rinko Hospital \\ 1-114-3 Momoyama-cho, higashi-ku, Niigata 950-8725, Japan \\ ORCID: 0000-0003-3366-9133
}

\section{Corresponding author}

\section{Hirotsugu Ohashi}

Department of Orthopaedic Surgery, Osaka Saiseikai Nakatsu Hospital

2-10-39, Shibata, Kita-ku, Osaka 530-0012 Japan

e-mail: hohashi@grace.ocn.ne.jp

telephone: +81-6-6372-0333

fax: +81-6-6372-0339 


\section{Abstract}

\section{Background}

3 A triple-tapered polished femoral stem was implanted with line-to-line cementing

4 technique. The purpose of this study was to determine the survivorship, loosening

5 rate, stem subsidence, radiologic changes and clinical outcomes in the minimum ten-

6 year follow-up.

\section{$7 \quad$ Methods}

8 This was a retrospective study done in three institutes. Finally, 118 hips in 97

9 patients could be followed-up at the mean follow-up period of 126.9 months. The

10 survivorship, radiological and clinical outcomes were investigated.

\section{Results}

12 Radiologically, 107 hips (90.7\%) were categorized to Barrack cementing grade A, and

13108 stems $(91.5 \%)$ were inserted in neutral position. All hips were not loose and were

14 not revised due to aseptic loosening. Survival with revision for any reason as the

15 endpoint was $100 \%$ after 10 years. At the last follow-up, the mean subsidence was

$16 \quad 0.41 \mathrm{~mm}$, and the subsidence was less than $1 \mathrm{~mm}$ in 110 hips $(93.2 \%)$.

17 JOA hip score improved from $42.7 \pm 9.2$ points preoperatively to $92.9 \pm 6.8$ points at

18 the last follow-up. No patient complained thigh pain. 


\section{Conclusions}

20 Line-to-line cementing technique with use of a triple-tapered polished stem was

21 effective to achieve good cementation quality and centralization of the stem. The

22 subsidence was small, and the minimum ten-year results were excellent without any

23 failures related to the stem.

24

25 Trial registration: Retrospectively registered

26

27 Keywords: Total hip arthroplasty, Triple-tapered polished femoral stem, Line-to-line

cementing technique, Subsidence

29

30

31

32

33

34

35

36 
Since the cement fixation system of femoral stems for total hip arthroplasty (THA) was established in the 1960s, a variety of different concepts have been applied to the development of the femoral stems. In these concepts, main topics are stem design and cement mantle thickness. In terms of stem design, cemented femoral stems can be broadly divided into two designs that achieve fixation as a composite beam and those that function as a taperslip device [1]. Recent studies of polished tapered cemented stems have reported superior long-term clinical outcomes from the systematic review [2], and significant survival advantages in the registry data [3]. Originally, double-tapered polished stems, such as the Exeter stem and the CPT stem, were developed. Their long-term good clinical results have been previously reported [4-6], while the bone loss in the calcar region around double-tapered stem was concerning [7]. A triple-tapered cemented stem was designed with the intention of loading the proximal femur, thereby reducing proximal bone loss [8]. Buckland et al. [9] measured bone mineral density (BMD) around a triple-tapered stem. The marked loss in BMD occurred in zone 1 and 7 within 9 months postoperatively, while zones 6 and 7 showed a recovery 
delayed recovery in BMD at 18 months.

56 The second topic of cemented stem is cement mantle thickness. It is still unclear

57 whether thickening the cement mantle leads to better outcomes. Many studies have

58 reported good outcomes for a cement mantle thickness of at least $2 \mathrm{~mm}$ [10-13], while

59 a favorable outcome with a thin cement mantle was also reported as 'French paradox'

$60[14,15]$. Line-to-line cementing technique means preparation of the femoral canal

61 using the largest possible broach and implantation of a stem with the same

62 dimensions as the broach. It is reported that line-to-line cementing technique in

63 human cadaver femora resulted in a mean thickness of cement of $3.1 \mathrm{~mm}$, and the

64 cement was directly supported by cortical bone or cortical bone with less than $1 \mathrm{~mm}$

65 of cancellous bone interposed in over 90\% of thin cement mantle areas [16]. This

66 technique also can achieve the pressurization of the cement into cancellous bone

67 during insertion of the implant [17]. These results indicate that both polished

68 tapered stem design and line-to-line cementing technique might bring about

69 successful long-term outcomes.

70 The purpose of this study was to determine the survivorship, loosening rate, stem

71 subsidence, radiologic changes and clinical outcomes in the minimum ten-year

72 follow-up of a triple-tapered polished stem implanted with line-to-line cementing 
73 technique. These results were compared with those of the other polished tapered

74 stems.

\section{$75 \quad$ Materials and Methods}

76 The research protocol of this retrospective study was in compliance with the Helsinki

77 Declaration. The institutional review board of Osaka Saiseikai Nakatsu Hospital

78 approved this study. Informed consent was obtained from all patients who

79 participated in this study.

80 From February 2009 to October 2010, consecutive 186 hips in 162 patients

81 underwent THA with a femoral stem (Trilliance, B.Braun Aesculap, Tuttlingen,

82 Germany) fixed with line-to-line cementing technique. This stem was made of $\mathrm{CoCr}$

83 with a highly polished surface (Ra $0.01 \mathrm{~mm}$ ) and a quadrangular section (Fig. 1).

84 Twelve patients died, 14 patients could not visit due to the comorbid disorders, 18

85 patients could not visit due to long distance to the institutes, and 21 patients were

86 lost to follow-up. Finally, 118 hips in 97 patients could be followed-up at longer than

87 ten years postoperatively (Fig. 2). The patients demographics, diagnosis, and

88 surgical approaches were shown in Table 1. No patient received prior surgery to the

89 hip. A type of cup and bearing materials were chosen according to the surgeons'

90 preference (Table 2). The heads used were 22, 26, 28 and $32 \mathrm{~mm}$ in diameter. Femoral 
91 canal was prepared using the largest possible broach, and bone plug or polyethylene

92 cement plug was placed at $1 \mathrm{~cm}$ distal to the stem tip. After pulse lavage, vacuum

93 mixed bone cement was introduced in a retrograde fashion. The femoral stem was

94 inserted without a distal centralizer.

95 Clinical and radiological evaluation was undertaken preoperatively and at 3 weeks

96 (baseline radiograph) and every year. At each follow-up visit, the patients had a

97 physical examination by the operating surgeons and the functional results were

98 evaluated using Japanese Orthopaedic Association hip score (JOA hip score, full

99 mark=100) [18]. Anteroposterior radiograph of the pelvis with the patient supine

100 position was obtained, and all the radiographs were examined independently by the

101 three authors. The cementing technique was assessed using the grading of Barrack

102 et al. [19]. The alignment of the stem was referenced from the axial alignment of the

103 femur, and the alignment was assumed to be neutral within 3 degrees from co-

104 linearity. On the final radiographs, the presence and evolution of radiolucent lines

105 and cortical thickening in any of the seven zones described by Gruen et al. [20] was

106 evaluated. Loosening of the femoral component was defined according to the criteria

107 of Harris et al. [21] which included subsidence of the stem greater than $3 \mathrm{~mm}$,

108 fracture of the cement mantle, and a complete radiolucent line greater than $2 \mathrm{~mm}$ or 
109 a radiolucent line in zone 1 greater than $2 \mathrm{~mm}$ in width. Periprosthetic cystic or

110 scalloped lesions larger than $2 \mathrm{~mm}$ in diameter which had not been present on the

111 immediate post-operative radiograph were defined as osteolysis. Subsidence of the

112 stem was measured on magnified images calibrated using the known size of the

113 femoral head. The radiological landmarks were the greater trochanter, the

114 proximolateral cement mantle and the shoulder of the prosthesis, as described by

115 the Exeter group [22].

116 All data were collected and analyzed using the Microsoft Excel Software (Microsoft

117 Corporation, Redmond, WA). Kaplan-Meier survival analyses (EZR, Saitama

118 Medical Center, Jichi Medical University, Saitama, Japan) were used to evaluate the

119 cumulative stem survivorship and performed for any reasons, and aseptic loosening.

120 Results

121 According to the Barrack cementing grade, 107 hips were categorized to grade A, 11

hips were categorized to grade B. Stem was inserted in neutral position in 108 hips,

123 in valgus in 7 hips, and in varus in 3 hips. Radiolucent lines and osteolysis were not

124 observed in any hips. All hips were not loose and were not revised due to any reasons

125 (Fig. 3). Cortical thickening was observed in one hip at zones 3 and 5. Fracture of

126 the cement mantle was not observed. No post-operative complication occurred, such 
127 as deep venous thrombosis, and heterotopic ossification.

128 Survival with stem revision for any reasons as the endpoint was $100 \%$. At the last

129 follow-up, the mean subsidence was $0.41 \mathrm{~mm}(0 \mathrm{~mm}$ to $1.9 \mathrm{~mm})$. In most of the hips,

130 the subsidence was less than $1 \mathrm{~mm}$ (Table 3 ).

131 JOA hip score improved from $42.7 \pm 9.2$ points preoperatively to $92.9 \pm 6.8$ points at

132 the last follow-up. No patient complained thigh pain.

133 Discussion

134 In this study, survival with revision for any reasons as the endpoint was $100 \%$. The

135 most widely used polished tapered femoral component, Exeter stem, showed that the

136 survival rate for all-cause revision of the stem was $96.8 \%$, and that for aseptic

137 loosening as the endpoint was $100 \%$ at 13.5 years [5]. From the report of C-stem,

138 there were no revision for stem loosening but two stems was revised for fracture at

139 a mean follow-up of 13 years [23]. CMK stem, implanted with line-to-line cementing

140 technique, marked the cumulative survival rate with revision of either component

141 for any reason as endpoint of $90.5 \%$ at 17 years [15]. Our long-term results would be

142 comparable to those of polished tapered stems.

143 Line-to-line cementing technique has some advantages. It can achieve the

144 pressurization of the cement into cancellous bone during insertion of the implant. 
145 While grade A cementation quality described by Barack was recognized in $49.6 \%$ and

$14673.6 \%$ when using the Exeter stems [5, 24], grade A was achieved in 90.7\% in our

147 study. Other advantage is centralization of the stem. Scheerlinck et al. reported line-

148 to-line stems without a distal centralizer were better aligned than undersized stems

149 fitted with a centralizer [17]. Cortical point contact during stem insertion may

150 improve alignment of the stem into the proximal medullary cavity. In our study,

$15191.5 \%$ was inserted in neutral position, and the CMK stem that was also implanted

152 with line-to-line cementing technique, was in a neutral position in $80.5 \%$ [15]. In

153 contrast, $65.3 \%$ was inserted within 2 degrees of varus or valgus in the Exeter stem

154 [24], and 61.7\% was in a neutral position in the C-stem [25].

155 The mean subsidence was $0.41 \mathrm{~mm}$ at the mean follow-up period of 126.9 months. It

156 was reported that the mean subsidence of Exeter stem was $1.2 \mathrm{~mm}$ at a minimum of

157 10-year follow-up [5]. The subsidence of C-stem AMT was reported to be $1.28 \mathrm{~mm}$ at

158 two years [26]. A hollow polymethyl-methacrylate centralizer was placed on the tip

159 of these stems. The use of centralizer and thick cement mantle might allow these

160 stems for subsidence. Subsidence remains a fundamental principle of the design of

161 taper-slip stem, which produces tensile hoop forces in the cement and compressive

162 stress at the cement-bone interface. On the other hand, the mean subsidence was 
$1630.63 \mathrm{~mm}$ in CMK stem, that had no centralizer and was implanted with line-to-line

164 cementing technique [15].

165 Cortical thickening was observed in one hip (0.8\%) in our study. The rate of cortical

166 thickening was reported from $0.5 \%$ to $40.2 \%[4,15,27]$. The rate of cortical

167 thickening was lower compared to those reported results. Cortical hypertrophy

168 might reflect the mechanical conditions around cemented femoral components,

169 however, this was not matched to poor outcome, and its clinical relevance is still

170 unclear.

171 The first limitation of the study is the uncontrolled retrospective study, and there

172 was no control group. Thus, the results were compared with those of the other

173 polished tapered stems. The Exeter stem and the CPT stem were double-tapered

174 stem, and the C-stem was triple-tapered stem. These stems were fixed using distal

175 centralizer with keeping cement mantle. The CMK stem was also double-tapered

176 stem and the line-to-line cementing technique was applied. Secondary, the follow-up

177 period was not enough to compare our results with reported long-term results. For

178 predicting the long-term survival of this femoral stem, we have to continue to

179 investigate the clinical and radiological outcomes.

180 In conclusion, line-to-line cementing technique with use of a triple-tapered polished 
181 stem was effective to achieve good cementation quality and centralization of the stem.

182 The subsidence was smaller than that of well-established polished tapered stems.

183 The minimum ten-year results were excellent without any failures related to the

184 stem. Further follow-up is needed to compare with results with longer-term follow-

185 up.

186

187

188 Declarations

189 Abbreviations

190 THA: Total hip arthroplasty, BMD: Bone mineral density, JOA hip score: Japanese

191 Orthopaedic Association hip score

192 Ethics approval and consent participate

193 The research protocol of this retrospective study was in compliance with the Helsinki

194 Declaration. The institutional review board of Osaka Saiseikai Nakatsu Hospital

195 approved this study. Informed consent was obtained from all patients who

196 participated in this study.

197 Consent for publication

198 Not applicable. 
200 The datasets used and anlysed during the current study are available from the

201 corresponding author on reasonable request.

\section{Competing interests}

203 The authors declare no conflicts of interest associated with this manuscript.

\section{Funding}

205 This research received no specific grant from any funding agency in the public,

206 commercial, or not-for-profit sectors.

\section{Authors'contribution}

208 HO designed the work, acquired and analysed the data, and was a major contributor

209 in writing the manuscript. SI and IM acquired and analysed the data, and

210 substantively revised the manuscript. All authors read and approved the final

211 manuscript.

212 Acknowledgements

213 Not applicable.

214 
1. Shah N, Porter M. Evolution of cemented stems. Orthopaedics 2005;28(8 Suppl):s819-825.

2. Bedard NA, Callaghan JJ, Stefl MD, Liu SS. Systematic review of literature of cemented femoral components: what is the durability at minimum 20 years follow-up? Clin Orthop Relat Res. 2015;473(2):563-571.

3. Kazi HA, Whitehouse SL, Howell JR, Timperley AJ. Not all cemented hips are the same: a register-based (NJR) comparison of taper-slip and composite beam femoral stems. Acta Orthop. 2019;90(3):214-219.

4. Petheram TG, Whitehouse SL, Kazi HA, et al. The Exeter universal cemented

5. Westerman RW, Whitehouse SL, Hubble MJW, Timperley AJ, Howell JR, Wilson

MJ. The Exeter V40 cemented femoral component at a minimum 10-year followup: the first 540 cases. Bone Joint J. 2018;100-B(8):1002-1009.

6. Junnila M, Laaksonen I, Eskelinen A, et al. Implant survival of the most common cemented total hip devices from the Nordic arthroplasty register association database. Acta Orthop. 2016;87(6):546-553. 
7. Morita D, Iwase T, Ito T. Bone resorption with cemented Exeter universal stem 2016;21(3):336-341.

8. Wroblewski BM, Siney PD, Fleming PA. Triple taper polished cemented stem in total hip arthroplasty: rationale for the design, surgical technique, and 7 years of

9. Buckland AJ, Dowsey MM, Stoney JD, Hardidge AJ, Ng KW, Choong PFM. total hip arthroplasty. J Arthroplasty 2010;25(7):1083-1090.

10. Ebramzadeh E, Sarmiento A, McKellop HA, Llinas A, Gogan W. The cement

12. Kawate K, Maloney WJ, Bragdon CR, S A Biggs SA, Jasty M, Harris WH.

11. Mulroy WF, Estok DM, Harris WH. Total hip arthroplasty with use of so-called second-generation cementing techniques. a fifteen-year-average follow-up study. 
13. Maloney WJ, Schmalzried T, Harris WH. Analysis of long-term cemented total

254 hip arthroplasty retrievals. Clin Orthop Relat Res. 2002;405:70-78.

14. Langlais F, Kerboull M, Sedel L, Ling RSM. The 'French paradox.' J Bone Joint Surg. 2003;85(1)-B:17-20.

15. El Masri F, Kerboull L, Kerboull M, Courpied JP, Hamadouche M. Is the so-called 'French paradox' a reality?: long-term survival and migration of the CharnleyKerboull stem cemented line-to-line. J Bone Joint Surg. 2010;92(3)-B:342-348.

16. Scheerlinck T, de Mey J, Deklerck R, Noble PC. CT analysis of defects of the cement mantle and alignment of the stem: in vitro comparison of CharnleyKerboull femoral hip implants inserted line-to-line and undersized in paired femora. J Bone Joint Surg. 2006;88(1)-B:19-25.

17. Skinner JA, Todo S, Taylor M, Wang JS, Pinskerova V, Scott G. Should the cement mantle around the femoral component be thick or thin? J Bone Joint Surg. 2003;85(1)-B:45-51.

18. Imura S. Evaluation chart of hip joint functions. J Jpn Orthop Assoc. 1995;69(9):864-867 (in Japanese)

19. Barrack RL, Mulroy RD Jr, Harris WH. Improved cementing techniques and femoral component loosening in young patients with hip arthroplasty. A 12-year 
radiographic review. J Bone Joint Surg. 1992;74(3)-B:385-389.

20. Gruen TA, McNeice GM, Amstutz HC. "Modes of failure" of cemented stem-type femoral components: a radiographic analysis of loosening. Clin Orthop Relat Res. 1979;141:17-27.

21. Harris WH, McGann WA. Loosening of the femoral component after use of the medullary-plug cementing technique. Follow-up note with a minimum five-year follow-up. J Bone Joint Surg. 1986;68(7)-A:1064-1066.

22. Fowler JL, Gie GA, Lee AJ, Ling RS. Experience with the Exeter total hip replacement since 1970. Orthop Clin North Am. 1988;19(3):477-489.

23. Purbach B, Kay PR, Siney PD, Fleming PA, Wroblewski BM. The C-stem in clinical practice: fifteen-year follow-up of a triple tapered polished cemented stem. J Arthroplasty 2013;28(8):1367-1371.

24. Young L, Duckett S, Dunn A. The use of the cemented Exeter Universal femoral stem in a district general hospital: a minimum ten-year follow-up. J Bone Joint Surg. 2009;91(2)-B:170-175.

25. Schuroff AA, Deeke M, Pedroni MA, Lupselo FS, Rodrigo Kunz E, Lima AM. Radiographic evaluation of cementation technique using polished, conical, tripletapered femoral stem in hip arthroplasty. Rev Bras Ortop. 2017;52(Suppl 1):40- 
26. Flatøy B, Röhrl SM, Rydinge J, Dahl J, Diep LM, Nordsletten L. Triple taper stem design shows promising fixation and bone remodeling characteristics: radiostereometric analysis in a randomised controlled trial. Bone Joint J. 2015;97(6)-B:755-761.

27. Yates PJ, Burston BJ, Whitley E, Bannister GC. Collarless polished tapered stem: clinical and radiological results at a minimum of ten years' follow-up. J Bone Joint Surg. 2008;90(1)-B:16-22.

297

298

299

300

301

302

303

304

305 
308 Fig. 1 Three views of a triple-tapered polished cemented stem, Trilliance

309 Fig. 2 The flowchart of patients in this study

310 Fig. 3 Post-operative anteroposterior radiographs of 62-year-old woman with

311 dysplastic hip osteoarthritis showing (a) well-aligned stem cemented with line-to-

312 line technique, (b) follow-up at 10 years without measurable subsidence of the stem

313

314

315

316

317

318

319

320

321

322

323

324

325

326

327

328

329

330

331

332

333

334

335

336 


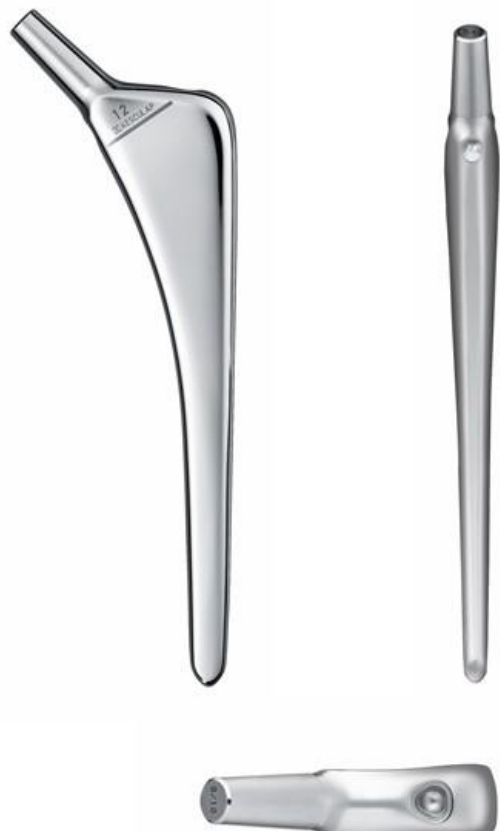

340

Fig. 1

341

342

343

344

345

346

347

348

349

350

351

352

353

354

355 


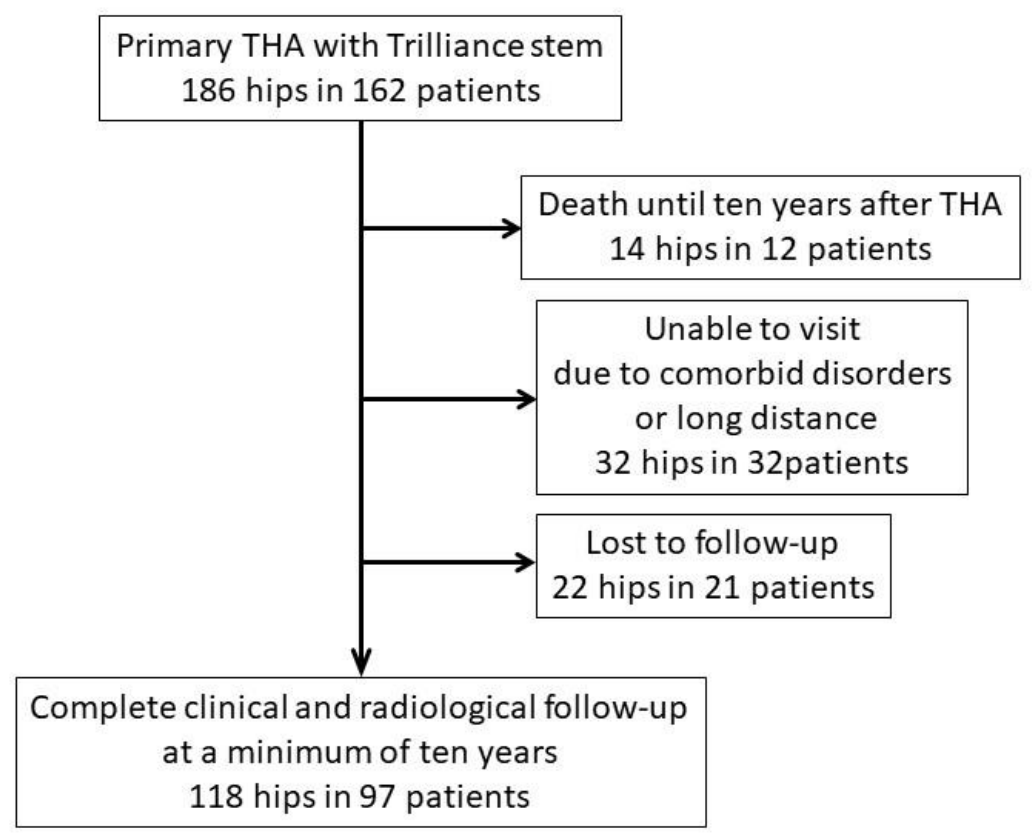




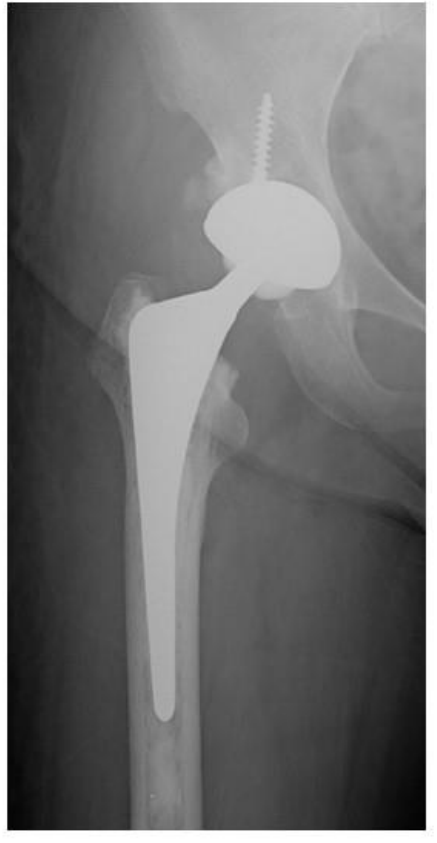

(a)

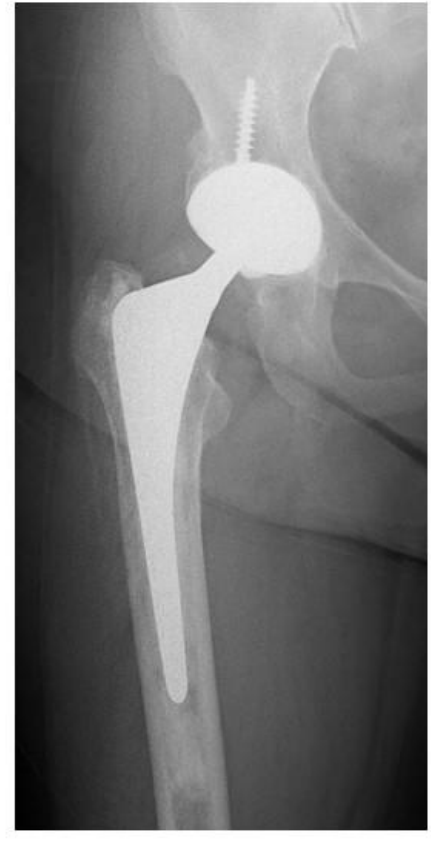

(b)

Fig. 3

379

380

381

382

383

384

385

386

387

388

389

390

391

392

393 
Table 1 Patient demographics, diagnosis, and surgical approaches

\begin{tabular}{|ll|}
\hline Demographics & \\
Number of hips & 118 hips \\
Age at operation (mean \pm SD, range) & $61.0 \pm 10.0(20-84)$ years \\
Sex & \\
Males & 18 hips \\
Females & 100 \\
Follow-up period (mean \pm SD, range) & $126.9 \pm 5.7(120-139)$ months \\
\hline
\end{tabular}

Diagnosis

Osteoarthritis

104 hips

Idiopathic osteonecrosis of femoral head $\quad 9$

Rheumatoid arthritis 2

Rapidly destructive coxarthritis

2

Miscellaneous 1

Approaches

Direct anterior approach 97 hips

Direct lateral approach 20

Transtrochanteric approach 1 
Table 2 Cups and types of articulation used in this study

417

\begin{tabular}{|l|r|}
\hline Cup & \\
\hline Plasmacup & 68 hips \\
\hline Contemporary & 5 \\
\hline Triad HA & 2 \\
\hline Trident & 43 \\
\hline
\end{tabular}

418

\begin{tabular}{|l|r|}
\hline Articulation & \\
\hline Ceramic / Ceramic & 68 hips \\
\hline Metal / Polyethylene & 50 \\
\hline
\end{tabular}

419

420

421

422

423

424

425

426

427

428

429

430

431

432

433

434

435

436

437

438

439

440 
444 Table 3 Number of hips in every $1 \mathrm{~mm}$ for subsidence

445

\begin{tabular}{|l|l|}
\hline Subsidence & \\
\hline $0 \mathrm{~mm}$ & 28 hips $(23.7 \%)$ \\
\hline $1 \mathrm{~mm}>\mathrm{S}$ & 82 hips $(69.5 \%)$ \\
\hline $2 \mathrm{~mm}>\mathrm{S} \geqq 1 \mathrm{~mm}$ & 8 hips $(6.8 \%)$ \\
\hline
\end{tabular}

446

S: subsidence

447

448

449 
Figures

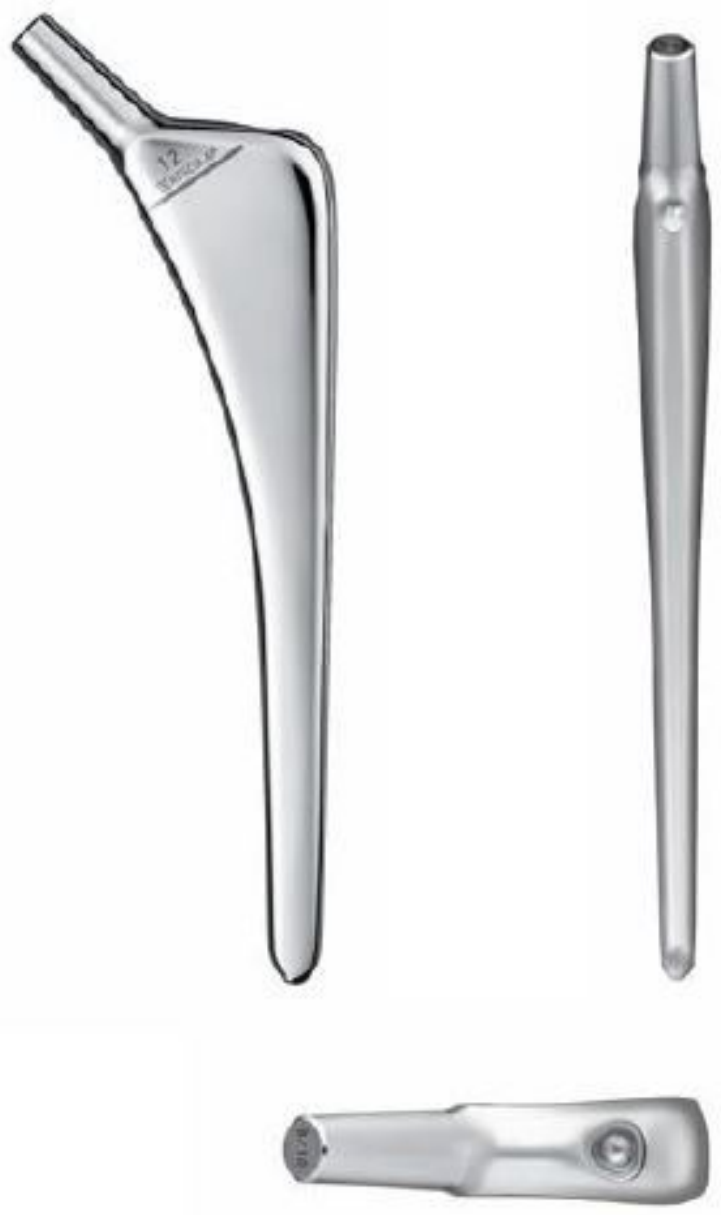

Fig. 1

Figure 1

Three views of a triple-tapered polished cemented stem, Trilliance 


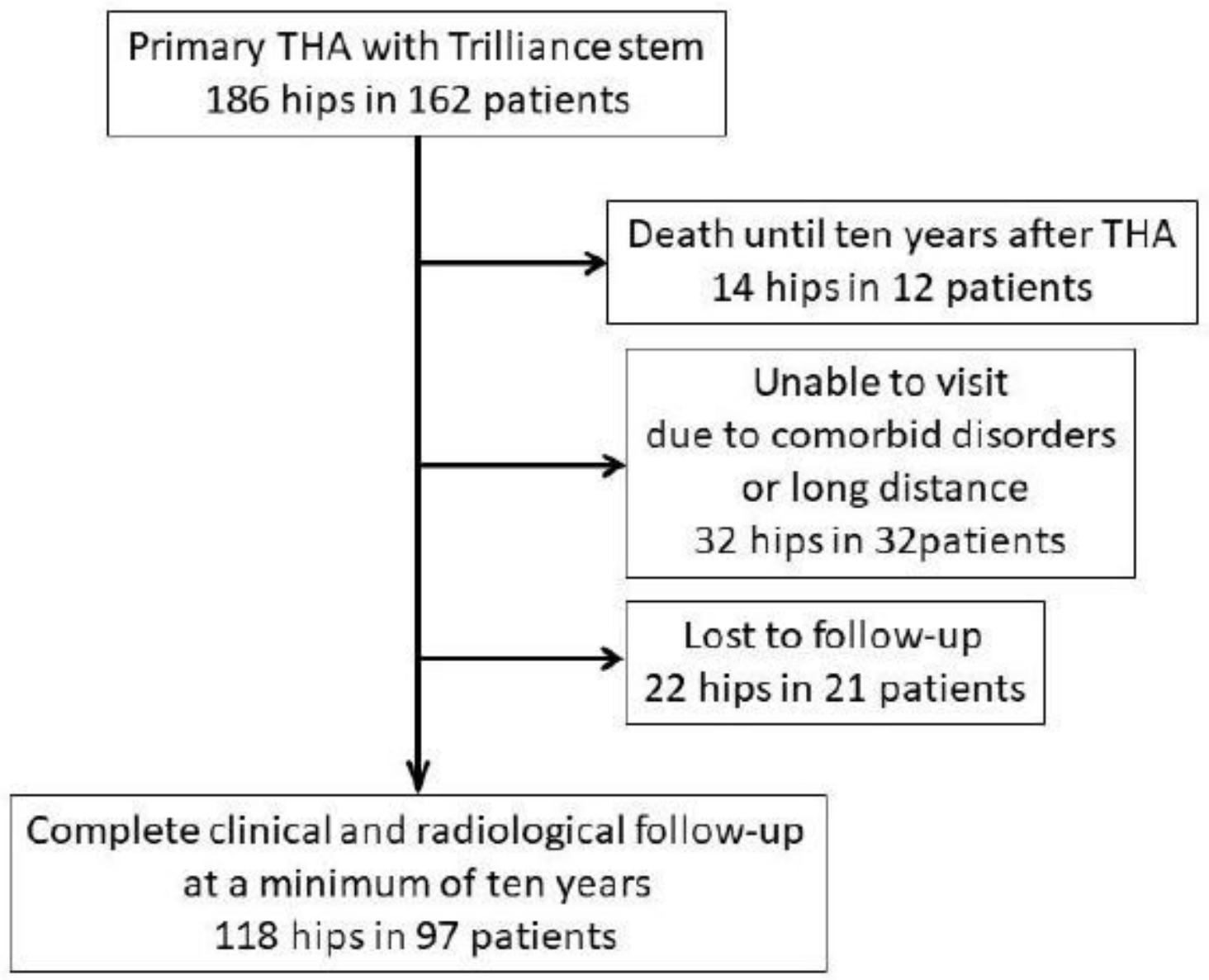

Fig. 2

Figure 2

The flowchart of patients in this study 


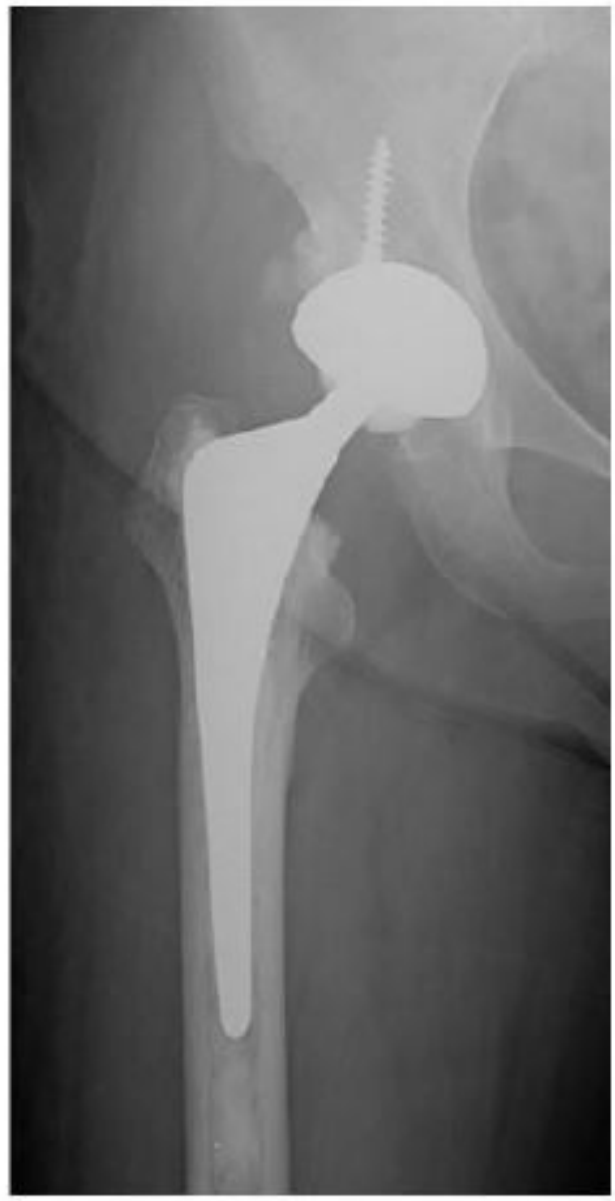

(a)

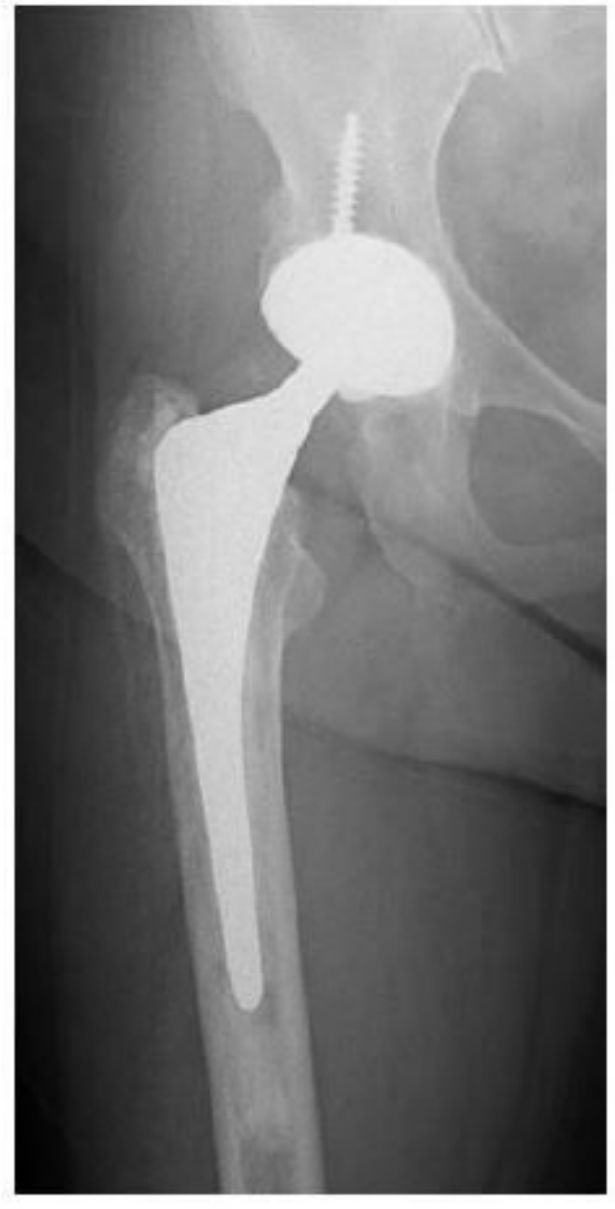

(b)

Fig. 3

\section{Figure 3}

Post-operative anteroposterior radiographs of 62-year-old woman with dysplastic hip osteoarthritis showing (a) well-aligned stem cemented with line-to-line technique, (b) follow-up at 10 years without measurable subsidence of the stem 